\title{
Social Movements and Democracy in Spain: Review of Democracia, dignidad y movimientos sociales. El surgimiento de la cultura cívica y la irrupción de los «indignados» en la vida pública. Rubén Díez y Enrique Laraña
}

\author{
Tiago Carvalho \\ Department of Social and Political Sciences. Scuola Normale Superiore. Italia/ltaly \\ tiago.lopescarvalho@sns.it
}

Over the last decade, Spain became one of the global hotspots for social movement contestation. The emergence of the 15M movement, or Indignados, was of significance not only in Spain, where it gave rise to the longest wave of mobilisation since the transition to the democracy but also internationally as its practices, repertoires and discourses became the blueprint for Occupy movements around the world. In Spain, the Indignados movement unleashed protest potential that transformed mobilisations between 2011 and 2014. The potency of these protests led to a shift in the public debate and the emergence of new parties such as Podemos and Ciudadanos. The $15 \mathrm{M}$ was not only a consequence of austerity under the Great Recession. It also transformed democracy, bringing to the fore new frames and repertoires that impacted institutional politics.

The 15M in Spain resulted from a combination of two crises: (1) the prolonged effects of the 2007/8 world financial crisis, and (2) the evergrowing dissatisfaction with political parties and institutions (both national and European) due to how these actors managed the effects of the Great Recession. These elements were present critique in the movement's public discourse: not only they fought for social justice as they criticised representative democracy. In addition to the criticism that developed with the overall anti-austerity mobilisations in the southern European countries, in Spain austerity politics led to a constitutional crisis that affected not only the party system, but also the territorial model of governance that emerged with the transition to democracy and that it is visible in the Catalan conflict (Miley, 2017). Moreover, at the very core of $15 \mathrm{M}$ actions was questioning and re-framing of the memory of the transition (Korne- tis, 2014). Consequently, Spain was plagued with multiple, simultaneous and interacting crises that encompassed both institutional and territorial dimensions, throwing the whole political apparatus into question.

Therefore, due to the impact of 15M's spectacular and prominent mobilisations in Spain, it is not surprising that there has been a large amount of published research on the topic since 2011. If early research could be seen to reproduce some of the movement's discourse of spontaneity and novelty (Fominaya, 2014), much of the current research enquires as to the role and increasing activity of protest movements in Spanish democracy, particularly when past research tended to consider Spain as having a weak civil society.

The publication of Díez and Laraña's book —Democracia, dignidad y movimientos sociales. El surgimiento de la cultura cívica y la irrupción de los «indignados» en la vida pública- is therefore an important contribution to the debate on the role played by social movements and civil society in the Spanish democracy. Despite other works in the field, none matches the analytical depth or historical contextualisation of the 15M that this book provides. Departing from a constructivist approach, the authors point to the cognitive and symbolic aspects of collective action that are put aside by most structural readings of social movements.

Díez and Laraña propose that since the transition to democracy a civic culture emerged in Spain. In their view, this resulted in the autonomy of "civil society" vis-à-vis the State, which ensured an increasing persuasion-capacity of social movements' frames. Therefore, in a Tocquevillian-inspired approach, they suggest that this guarantees the vitality of civil society and public virtues, thereby ques- 
tioning the previously existing image of a weak civil society. Social movements, being reflexive agents, ensure the resonance, meaning and persuasion in the public sphere. As a result, in their view, the $15 \mathrm{M}$ played an essential role in expanding civic culture and, therefore, deepening democratisation among citizens.

This book comprises four distinct parts. In the first part of the book, the authors build up an analytical framework that relies on a cross-over of three theoretical traditions: reflexive modernisation, civic culture, and social movements and frame analysis. In combining these, Díez and Laraña build a theoretical approach that enables an understanding of social movements within a macro-analysis of social change, while viewing movements as reflexive agents and important carriers of change. Methodologically, a triangulation of ethnography, focus groups, interviews, survey data and frame analysis brings together a vast array of data collected. The evidence becomes cumulative and self-reinforcing, with its multiple elements referring to both micro and macro perspectives.

The second part of the book comprises two key chapters, with both a historical and sociological component, in which the authors question the existence of an apathetic civil society in Spain and point out to the progressive emergence of a civic culture, rooted in the transition process to democracy in the 1970s. The authors combine a reconstruction of the mobilisation processes since Spain's transition to democracy with contextual, structural and more immediate factors that led to the anti-austerity cycle of protest in 2011-2014.

In addition to the processes of modernisation and political transition, the authors focus from the 1980s onwards on the antimilitary movements, students, and social centres that contributed to the formation of the $15 \mathrm{M}$, as well as some key movement organisations in the development and expansion of civic culture among citizens in the mid-1990s, like the civic organisations against ETA's terrorism.

The third part presents the four core empirical chapters of the book that discuss 15M in detail. Each of the chapters is dedicated to a single overarching theme, whereby their approach materialises and highlights the "intersubjective dynamics", the uses of language and, finally, its resonance at the macro level. The first chapter of this part puts the eruption of the 15M into public life into a broad and encompassing frame, which is followed by a chapter that identifies the composition of the movement. The third chapter discusses the elements of the collective identity of the 15M and its expansion, and finally, the transnational aspects of the movement over time.

A widespread public critique of political parties and institutions coincided with the ascendance of the 15M. This dissatisfaction was shared by multiple groups and had a broad involvement and support of citizens. This critique incorporated a mobilisation frame in which political regeneration and life-chances were at the core, supported most notably by non-violent principles of action and engaging participation. When identifying the "social basis of indignation", i. e., of those participating in the 15M protests - using a survey from the Centro de Investigaciones Sociológicas - the authors highlight that the participants on $15 \mathrm{M}$ were likely: from a city, educated, young, and employed. Despite being dissatisfied with political institutions actors and banks, these participants were well informed about politics overall and positioned themselves on the left of the political spectrum. The authors conclude that already-engaged citizens in associations and NGOs were more prone to participate in the demonstrations of the 15M.

The third empirical chapter of this part comprises a frame analysis of collective identity. Díez and Laraña map the 15M frames of action and how these changed over the cycle of protest. The underlying idea is that contestation of austerity between 2011 and 2015 involved multiple actors, repertoires and demands. In 2011, the scaling up of multiple latent protest groups from previous decades produced the 15M: these groups used digital platforms and emphasised the importance of democracy against a political system they felt was unfair and corrupt. Nonetheless, as the authors show, their frame of action did not stagnate, and between 2012 and 2013, adding to the previous claims, multiple actors contested more clearly austerity and the economic consequences of the crisis. Finally, in 2014, multiple platforms reunited the dispersed and multi-issue groups that devel- 
oped throughout 2012 and 2013, combining them in a single group to organise protest demonstrations and marches. It is at this point that political parties, both at the national and municipal level, emerged, emanating from the $15 \mathrm{M}$. It is important to note that this chapter shows that in Spain a plurality of interrelated actors, repertoires and claims co-existed in contesting austerity.

Finally, in the last empirical chapter, the authors go beyond Spain to make a broader argument: that the $15 \mathrm{M}$ was not only the result of the abovereferred dynamics at the national level but was also a part of broader dynamics since the 1960s that connects them to the emergence of the New Left. Furthermore, by broadening up their research scope, the authors show how the Spanish movements were part of a broader transnational movement that during the last decade organised transnational marches and events across the world. These events resulted not only from resonance and diffusion of frames but also from a shared view of the common problems that inflict countries worldwide, such as the collusion of political and economic elites and declining quality of democracy.

The contribution of Díez and Laraña is of importance. They challenge some of the presentist narratives about social movements in Spain - which view them as spontaneous, novel and spectacular events, through carefully discussing a wide range of actors and activities over a long period, that forms part of a more extensive historical process. Their argument links broad issues and essential topics in the field of social movements, such as continuity and disruption between different cycles of protest, the role of collective action in democracy, and the quality of democracy. Moreover, escaping elitist and party-centred approaches, the book presents social movements as central actor shaping democratic regimes.

I would argue that this book could be positioned in broader academic debates about the nature of collective action in Spanish democracy. If in the transitology literature, movements were almost absent, the tide seems now to have turned: there is now a recognition of the role played by bottomup mobilisations during this period. The visibility of protest over the last decade made several academic works consider the role of contention in democracy.
Data from the European Social Survey have consistently shown that since 2002 Spain has some of the highest values of protest in Europe, i. e., protest activities constitute one of the main forms of political engagement in this country. Therefore, it is not surprising that the $15 \mathrm{M}$ was a movement central to the democratic dynamics under austerity. As such, several authors note that one of the main features of Spanish politics is the autonomy between protest movements and institutional politics (Fishman, 2012; Flesher Fominaya, 2007; Riley \& Fernández, 2014). In line with these contributions, Díez and Laraña point out that the transition to democracy opened the space for autonomous movements to develop. In their view, the reflexive movements and the creation of a civic culture spread into society and block regressive movements. Criticising the top-down statist approach, the authors of this book point out how movements themselves are key actors in the process of political change.

Furthermore, thick and detailed description, covering systematically different dimensions and aspects of the Indignados movement, is a characteristic feature of this book. It is important to note that the social sciences are currently dominated by a positivistic model that entails very few detailed descriptions, and are rather more concerned to build up causal models. This is not to say that the latter is not necessary or valid, but rather that the social sciences ought to be pluralist in nature, where interpretative schemes and thick description are not forgotten. Whilst this has its virtues, it can also make this work less accessible to a wider readership. And indeed, most of the times the arguments made could have been made more directly. That said, I think the book deserves an English translation/version with a simpler structure and fewer chapters.

A final note on the tone of this book, which could be viewed as overoptimistic. It sees social and protest movements as essentially positive forces with the power to change democratic politics. However, the most recent wave of nationalist movements in Spain, of both Spanish and Catalan nationalism, appear to have plagued the country with a conflict that, far from being progressive and inclusive, is regressive and divisive. As such, how can the analytical framework developed in the book apply to more recent tendencies in Spain? Are these 
movements also reflexive agents that work towards modernisation and civic culture?

To conclude, this book is an invaluable contribution to the debate in the field and the most important book published so far on the dynamics of and around 15M. It constitutes a central piece of research for an understanding of the origins of the current Spanish political division - and an invitation to look at democracy from a bottom-up perspective.

\section{REFERENCES}

Díez, R., Laraña, E. (2017). Democracia, Dignidad y Movimientos Sociales. El Surgimiento de la Cultura Cívica y la Irrupción de los «Indignados» en la Vida Pública. Madrid: CIS.

Fishman, R. M. (2012b). On the Significance of Public Protest in Spanish Democracy. In J. Navarro, F. Pallarès, F. Requejo (eds.), Democràcia, Política I Societat: Homenatge a Rosa Viros (pp. 351-366), Barcelona: Universitat Pompeu Fabra.

Flesher Fominaya, C. (2007). Autonomous Movements and the Institutional Left: Two Approaches in Tension in Madrid's Anti-Globalization Network. South European Society and Politics, 12(3), 335-358.

Flesher Fominaya, C. (2014). Debunking Spontaneity: Spain's 15-M/Indignados as Autonomous Movement. Social Movement Studies, 14(2), 142-163.

Miley, T. J. (2017). Austerity Politics and Constitutional Crisis In Spain. European Politics and Society, 18(2), 263-283.

Kornetis, K. (2014). "Is there a future in this past?" Analyzing 15M's intricate relation to the Transición. Spanish Journal of Cultural Studies, 15(1-2), 83-98.

Riley, D., Fernández, J. J. (2014). Beyond Strong and Weak: Rethinking Postdictatorship Civil Societies. American Journal of Sociology, 120, 432-503. 